\title{
HERMAFRODITISMO E INTERSEXUALIDADE NA FOTOGRAFIA MÉDICA PORTUGUESA
}

\author{
António Fernando Cascais
}

\begin{abstract}
Resumo
O interesse da Cultura Visual da Medicina por imagens fotográficas de hermafroditas remonta no nosso País aos primórdios da fotografia médica, com o registo fotográfico de um caso de hermafroditismo masculino estudado em 1864 por Carlos Miguel Augusto May Figueira (1829-1913) no Serviço de Clínica Médica do Hospital de S. José, escassos quatro anos após a obra tida por seminal de Félix Nadar em 1860. Este estudo é um dos elementos fundadores de uma scientia sexualis portuguesa, no âmbito mais amplo da sexologia moderna descrita por Michel Foucault, que entre nós se desenvolve sensivelmente entre meados do século XIX e as décadas de 1930-1940. A linhagem temática de pesquisa sobre o hermafroditismo e à intersexualidade assim aberta por May Figueira foi prosseguida por vários clínicos e cientistas portugueses desde a década inicial do século XX até aos anos de 1940. O propósito último da fotografia médica de hermafroditas era a preparação da intervenção cirúrgica corretiva no respeito absoluto do dimorfismo sexual binário que já o próprio diagnóstico nunca ousava pôr em causa.
\end{abstract}

\section{PaLAVRAS-Chave}

Hermafroditismo; intersexualidade; medicina; fotografia; género

\begin{abstract}
The interest harboured by the Visual Culture of Medicine in photographic images of hermaphrodites dates back in Portugal to the birth of medical photography, with the photographic recording of a case of male hermaphroditism, that was studied in 1864 by Carlos Miguel Augusto May Figueira (1829-1913) at the Medical Clinic Service of the S. José Hospital, only four years after the publication of the seminal work on this topic by Félix Nadar. This 1864 study is one of the founding elements of a Portuguese scientia sexualis in the wider context of modern sexology, as described by Michel Foucault, that evolved in Portugal between the mid-1 $9^{\text {th }}$ century and the 1930s-1940s. The thematic lineage of research into hermaphroditism and intersexuality, initiated by May Figueira was subsequently pursued by Portuguese clinicians and medical scientists from the first decade of the $20^{\text {th }}$ century up until the 1940 . The ultimate goal of the medical photographic recording of hermaphrodites was to pave the way to surgical correction, in strict compliance with binary sexual dimorphism that the original diagnosis never dared to question.
\end{abstract}

\section{KEYWORDS}

Hermaphroditism; intersexuality; medicine; photography; gender 
O interesse da Cultura Visual da Medicina por imagens fotográficas de hermafroditas remonta no nosso País aos primórdios da fotografia médica, com o registo fotográfico de um caso de hermafroditismo masculino estudado em 1864 por Carlos Miguel Augusto May Figueira (1829-1913) no Serviço de Clínica Médica do Hospital de S. José. Pioneiro da fotografia médica em Portugal, May Figueira distinguiu-se sobremaneira pela microfotografia, com que o distingue a historiografia da Medicina portuguesa. De acordo com o que atualmente se sabe, o recurso à fotografia pela ciência e arte médica nacional remonta ao virar das décadas de 1850 para 1860, mas tem-se por adquirido que o seu uso, excecional no início, só se generaliza a partir dos anos de 1880. May Figueira foi um dos raros pioneiros que individualmente se serviu dela de forma sistemática na histologia onde se tinha especializado (Pimentel, 1996, pp. 6-9). Porventura menos apreciado, mas não menos importante, é o seu estudo "Observação de um caso de hermafroditismo masculino colhida no Hospital de S. José", publicado na Gazeta Médica de Lisboa (Figueira, 1864), escassos quatro anos após a obra tida por seminal de Félix Nadar em 1860. Nada indica que May Figueira tivesse tido conhecimento da existência das fotografias de Nadar, nem também do célebre caso coevo de Herculine Barbin / Alexina B., que também foi fotografada (Dreger, 1998, pp. 19-20) e cujo diário foi inicialmente dado à estampa em versão consabidamente expurgada (e a única que resta) por Ambroise Tardieu em 1872, de que Nadar possuía um exemplar (Le Mens, 2009, p. 14) e que Michel Foucault republicou em 1978 (Barbin, 1978).

O estudo de May Figueira, onde se inclui um conjunto fotográfico com imagens da pessoa em vida e de peças anatómicas recolhidas post-mortem (Figura 1), deve ser considerado um dos elementos de um muito mais vasto conjunto de componentes textuais (tratados de referência, artigos, teses, etc.) e imagéticos (fotografia médica, psiquiátrica e forense, objetos visuais tais como preparações anatómicas, desenhos e esquemas, fichas de identificação judiciária, etc.) provenientes de múltiplas fontes, todos eles fundadores de uma scientia sexualis portuguesa, no âmbito mais amplo da sexologia moderna descrita por Michel Foucault, que entre nós se desenvolve sensivelmente entre meados do século XIX e as décadas de 1930-1940. As fotografias de May Figueira correspondem à interrogação dos médicos que, por volta de 1860, se punha em termos de identidade, a qual não se referia às caraterísticas singulares que diferenciariam o indivíduo dos demais, mas precisamente àquelas que o tornavam idêntico aos tipos estabelecidos pelas diferentes ciências de classificação taxonómica dos sinais visíveis, como a fisiognomia (Le Mens, 2009, p. 21). A fotografia médica e científica dos hermafroditas que pareciam pôr em causa esses sistemas de classificação visa pois restituí-los à normalidade, tais como a restante fotografia judiciária e policial dos indivíduos perigosos (prostitutas, delinquentes, homossexuais, vadios, alcoólicos, doentes mentais, etc.) e que a técnica do bertillonage elevou a uma autêntica ciência iconográfica (Le Mens, 2009, p. 22). A linhagem temática de pesquisa assim aberta - a fotografia do hermafroditismo e da intersexualidade - amplamente representada no plano internacional e onde se contam Magnus Hirschfeld e Louis Ombrédane, foi seguida na Cultura Visual da Medicina em Portugal, que os citava, designadamente por clínicos como Adriano Xavier Lopes Vieira 
(Vieira, 1906), na primeira década do século XX, Maria Evangelina da Silva Pinto, nos anos de 1910 (Pinto, 1915), Pedro Chaves (Chaves, 1925) e Asdrúbal de Aguiar (Aguiar, 1928), na década de 1920, Vítor Fontes (Fontes, 1926; Fontes, 1937), nas décadas de 1920 e 1930, Joaquim Alberto Pires de Lima (Lima, 1930; Lima, 1937a; Lima, 1937b; Lima, 1939), Amândio Tavares (Lima \& Tavares, 1930) e Mark Athias (Athias, 1937), nos anos de 1930, Jorge Alberto Martins D'Alte (D'Alte, 1945), M. Ferreira de Mira (Mira, 1933), José Bacalhau (Bacalhau, 1946), António Carneiro de Moura e Ludgero Pinto Basto (Basto \& Moura, 1945; Basto, 1949), na década de 1940.

As imagens fotográficas do hermafroditismo e da intersexualidade ilustram de forma evidente o fenómeno mais vasto de uma política de captura tecnocientífica dos fenómenos patológicos, e de alguma maneira desviantes, mas são incapazes de dissimular o voyeurismo mais ou menos subterraneamente comum à ciência, à cultura popular e às artes visuais. A fotografia médica do hermafroditismo e da intersexualidade torna-se plenamente inteligível no seio da ciência médica positivista, a qual, ao cruzar-se através dela com a arte e a técnica, define, no entanto, um regime de visibilidade que lhe é próprio e que se pode caraterizar de forma distintiva com minúcia e rigor. A fotografia médica dos hermafroditas pode ser entendida à luz de um paradigma indiciário definido por Carlo Ginzburg (1979) e retomado por Jonathan Crary (2001), na medida em que procura detetar os signos externos ou indícios que permitem captar o sentido profundo dos fenómenos, alçando-se ao estatuto de uma autêntica tecnociência iconográfica. No caso dos hermafroditas, trata-se de lhes estabelecer o "verdadeiro sexo" de pertença, e, por essa via, de lhes prescrever uma identidade expurgada de quaisquer ambiguidades sobre o pano-de-fundo estruturante da estrita polaridade binária dos sexos, isto é, de "procurar estabelecer num pólo estável - quer feminino, quer masculino - a identidade do sujeito. O meio fotográfico é duplamente eficaz para tanto: procura-se delimitar contornos anatómicos para tentar aproximá-los do feminino ou do masculino" (Le Mens, 2009, p. 21). May Figueira descreve o caso de Bernardina de Sena, falecida aos setenta e seis anos, caquética, após 43 dias de internamento no Hospital de S. José, em Lisboa, onde tinha dado entrada em 18 de Janeiro de 1863:

tinha estatura mediana, physionomia varonil muito enrugada, cabeça volumosa com um unico dente na maxilla inferior, voz com o timbre um tanto grave. O systema piloso nas differentes partes do corpo era pouco desenvolvido, a não ser na cara, em que apresentava bigode russo e barba quasi toda branca bastante abundante, do comprimento de 4 a 6 centimetros. (...) pretendia porém ter sido menstruada, o que se conheceu por fim ser falso pelo exame anatomico dos orgãos sexuaes feito depois da morte (...) com pouca tendencia para todos os mesteres proprios do sexo feminino. Não me foi possivel saber outros pormenores acerca do seu modo de vida antes de chegar a velhice, senão que em 1833 föra encontrada de noite pelos empregados da policia, que a julgaram ser um homem vestido de mulher, em consequencia da barba preta e bigode que já então possuia, e por isso a 
prenderam, e mandaram que fosse revistada por uma mulher de confiança, que depois de a examinar afiançou que Bernardina de Senna era realmente do sexo feminino. (...) Nunca se the pôde conhecer em epocha alguma da vida tendencias amorosas para qualquer dos sexos; apenas se sabe que aborrecia os homens, a ponto de sentir desagrado quando lhe noticiavam o nascimento de alguma creança do sexo masculino, manifestando contentamento quando pelo contrario era do sexo feminino. Fugia quanto podia de ouvir fallar em casamentos. Viveu alguns annos em companhia de uma mulher com quem se dava muito bem, que annos depois se suicidou, deitando-se ao Tejo. Durante toda a sua vida teve a consciencia de que era mulher, e todos os seus parentes e conhecidos sempre como tal a receberam. (...) O habito externo do cadaver apresentava, como mais notavel, alem de que referi na historia pregressa, o que diz respeito aos orgãos genitaes. Verificou-se a completa ausencia de glandulas mamarias e os bicos das mamas mui pouco proeminentes. O systema piloso do corpo pouco desenvolvido ainda mesmo nos orgãos sexuaes; pelo contrario a face mostrava a mesma barba e bigode que se notava em vida, e quem olhasse unicamente para a cabeça diria ser a de um homem velho. A bacia, tanto interna como externamente, apresentava a conformação da do homem adulto. Os orgãos da geração vistos superficialmente poderiam ser considerados como femininos, por isso que o escroto era completamente fendido desde o supposto clytoris ate ao anus, simulando perfeitamente os.grandes labios de uma mulher velha bastante flacidos e distendidos. Na parte superior via-se um pequeno pénis do comprimento de 3 centimetros com uma glande imperforada do tamanho de uma grande ervilha, tendo porem uma leve depressão ou marca no ponto aonde existe o meato urinario no homem; esta glande era coberta ate á parte media por um prepucio do tamanho proporcional ao d'aquelle orgão. Dos lados partiam umas finas e mui curtas pregas, que de longe poderiam ser tomadas por nymphas. Apertando o penis entre os dedos, sentiam-se os corpos cavernosos que caminhavam ate a parte inferior da arcada pubica. Este penis assim conformado tinha a configuração de um clytoris um tanto desenvolvido. Pela sua parte inferior não havia raphe, mas sim uma fita cuja estructura era mais parecida com a mucosa uretral, do que com a epiderme contigua, aonde foi facil encontrar as differentes aberturas das lacunas de Morgagni, sendo a todos os respeitos inteiramente similhante a uma uretra de homem, que se tivesse aberto no sentido longitudinal. Esta face inferior do penis, que tinha de comprimento $\mathrm{O}^{\mathrm{m}}, \mathrm{O} 55$ terminava abaixo da arcada pubica pelo orifício de um canal ou meato urinario, constituindo um verdadeiro hypospadias e simulando ao mesmo tempo a uretra feminina, cujo comprimento até a sua entrada na bexiga era de $\mathrm{O}^{m}, 025$. Caminhando para a parte inferior e posterior encontrava-se logo abaixo do meato urinario uma abertura como a de uma 
vagina com $\mathrm{O}^{m}$, or de diametro, na qual podia apenas penetrar o dedo minimo, tendo de profundidade $\mathrm{O}^{\mathrm{m}}, \mathrm{O} 35$. O espaço comprehendido entre ella e o anus, isto é, o perineo, media $\mathrm{O}^{\mathrm{m}}, \mathrm{O} 4$. A entrada deste canal tinha o aspecto de uma vagina de creança, encontrando-se ali umas mui pequenas pregas analogas aos corpos myrtiformes. No interior d"elle notavam-se algumas finas rugas ou strias transversaes como as próprias da vagina, não contendo porém mucosidade alguma. Este mesmo canal terminava em fundo de saco, não apresentando o menor vestígio de abertura superior ou uterina. Dos lados desde o penis até proximo do anus estavam pendentes os dois corpos ou bolsas que simulavam, como já disse, os grandes labios de uma mulher velha, e que constituíam um verdadeiro escroto fendido. A pelle d'estes corpos era enrugada e flacida; feita a dissecção da bolsa direita achou-se na parte mais inferior um bem conformado testículo de adulto com todas as suas tunicas, contendo tambem uma pequena quantidade de liquido na tunica vaginal. Do epididymo partia o cordão spermatico até entrar no na nel inguinal correspondente. A observação microscopica do tecido d"aquelle orgão deu a estructura propria do testículo. (...) Com os orgãos sexuaes assim dispostos e obvio que este individuo, que toda a sua longa vida foi considerado como uma mulher, tendo elle mesmo consciencia disso, era um hermaphrodita masculino. É facil explicar a rasão por que logo depois do nascimento Bernardina de Senna foi julgada como pertencente ao sexo feminino, porque e sabido, e é mesmo frequente, que em muitos individuos os testículos nos primeiros tempos depois do nascimento conservam-se dentro da cavidade abdominal, circumstancia esta que muitas vezes acontece em individuos bem conformados, e é mesmo mui commum nas differentes especies de hermaphroditas, e só depois de um praso de tempo mais ou menos longo é que descem para o escroto. Comprehende-se agora facilmente que, tendo-se dado esta circumstancia no individuo em questão, como é mui provavel, e apresentando elle um escroto fendido com um canal analogo ao de uma vagina, fosse considerado no acto do nascimento como um individuo do sexo feminino, e como tal fosse tambem recebido durante toda a vida. Não me parece porem que alguma vez tivesse funcionado como mulher, porque se assim fosse a falsa vagina não apresentaria as exiguas dimensões que mencionei. Se teve occasião de funccionar como homem, ou se em algum tempo teve contratos com mulheres a ponto de chegar a ter ejaculações de semen, como a disposição dos orgãos plenamente o admittia, e o que não pude saber, apesar das miudas averiguações a que procedi. Parece comtudo que as suas tendencias e condições moraes, pelo menos nos ultimos annos, não davam margem a que se desconfiasse de tal. (Figueira, 1864, pp. 200-206) 


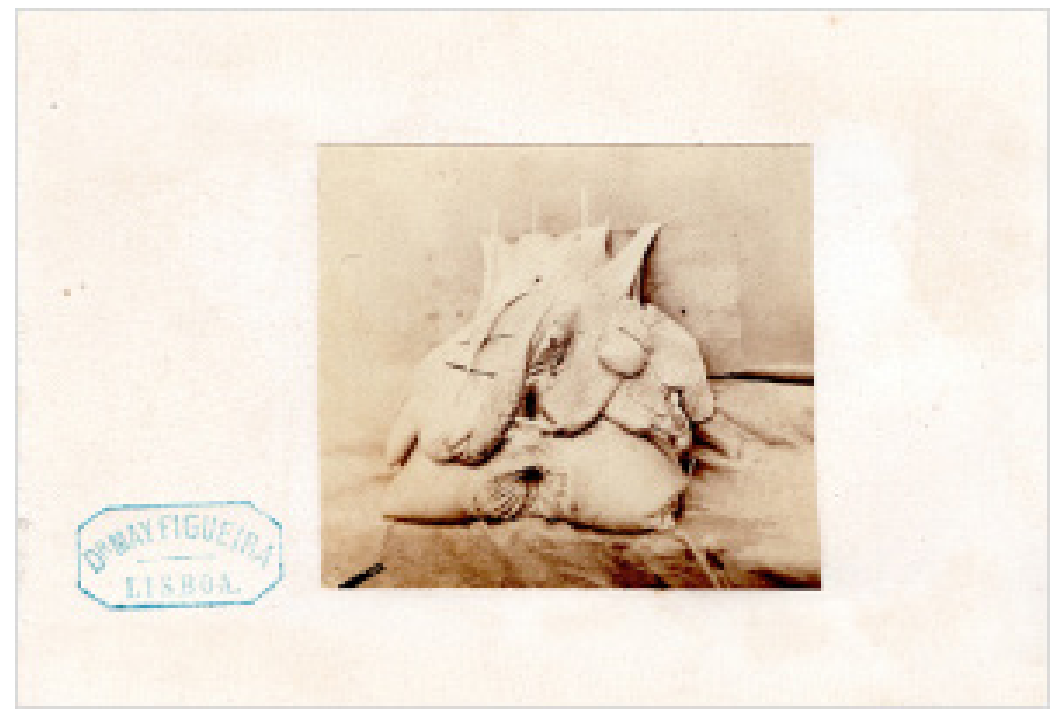

Figura 1: Necrópsia de Bernardina de Sena, por Carlos May Figueira em 1864 Fonte: Figueira, 1864

May Figueira, que mostra conhecer, entre outros, o caso célebre de Maria Rosina Goettlich (Figueira, 1864, pp. 237-238), reconhecido por Michel Foucault como um dos casos exemplares nos primórdios da história da medicalização do hermafroditismo e da intersexualidade, confirma que Bernardina de Sena preenche os critérios para ser incluída na categoria de verdadeiro hermafrodita masculino (Figueira, 1864, p. 236) tal como foi originalmente definida por Geoffroy Saint-Hilaire. E interroga-se acerca dos problemas médico-legais que o caso poderia levantar, caso Bernardina de Sena tivesse dado conta do seu verdadeiro sexo "na idade própria" (Figueira, 1864, p. 210), tais como: se estaria isento do recrutamento militar, se seria obrigado a casar se tivesse engravidado uma mulher, ou então se o seu vício de conformação teria sido motivo justificado de divórcio, e se teria direito a herdar um morgadio por morte do pai, retirando o privilégio da precedência a um eventual irmão mais novo até aí tido como primogénito varão. Tal como a generalidade dos colegas contemporâneos, o clínico apercebe-se que a descrição detalhada do sexo anatómico do paciente, por ele abordado num plano estritamente clínico, lhe permite decidir do seu futuro género social, cultural e jurídico (Le Mens, 2009, p. 23). E não por acaso: ao longo da história da medicalização do hermafroditismo
manteve-se sempre a crença que um corpo humano só pode ter um sexo e nada mais do que um se quiser ser socialmente admitido e legalmente re- conhecido. (...) Paradoxalmente, esta crença vem à luz mais do que nunca na nossa própria época, a do "sexo simulacro". (García \& Cleminson, 2012, p. 236)

Desde o português May Figueira e seus contemporâneos internacionais até à atual genética, que abriu a possibilidade de determinação cromossómica do sexo e do intersexo cromossómico em certos casos (a que não se reduzem, porém todos os estados intersexuais), a abordagem clínica do hermafroditismo e da intersexualidade foi-se dotando de instrumentos biotecnocientíficos cada vez mais sofisticados. Temos, por 
isso, que ressalvar sempre a distância que separa a biotecnociência atual dos tempos, para nós já recuados, de Geoffroy Saint-Hillaire e de May Figueira. Com efeito, dá-se hoje por adquirido que:

os estados intersexuais são situações raras com uma prevalência de 1 para 25000 nados vivos na Europa. Nas situações de ambiguidade sexual não é possível caraterizar, ao nascer, um indivíduo como sendo do sexo masculino ou feminino, baseado apenas no exame físico, pois coexistem nesse mesmo indivíduo elementos anatómicos com caraterísticas de ambos os sexos. A classificação destes estados intersexuais embora complexa fundamenta-se no cariótipo e na presença de gónadas. Habitualmente divide-se em cinco tipos: hermafroditismo verdadeiro, pseudohermafroditismo feminino, pseudohermafroditismo masculino, disgenesia gonadal pura e disgenesia gonadal mista. $O$ termo pseudohermafroditismo masculino refere-se a indivíduos $46 \mathrm{XY}$, que apesar da presença de testículos, apresentam diferentes graus de fenótipo feminino. A deficiente diferenciação masculina destes indivíduos pode ser devida à inadequada produção de testosterona, a uma insensibilidade parcial dos tecidos aos androgénios ou a uma deficiente produção ou acção da substância inibidora mulleriana (MIS). (Borges et al., 2006, p. 39)

Outra coisa são os referentes simbólico-culturais da abordagem biomédica cujas mudanças não acompanharam necessariamente e em rigoroso paralelo a evolução biotecnocientífica e que em certas situações continuam a enviesar fortemente toda a necessidade de "explicação" científica de fenómenos que se encontram saturados de significados culturais atinentes à essencial incoerência, ambiguidade e, logo, à ininteligibilidade de género de que ele é portador. Mencione-se tão só a polémica, não muito distante e decerto que não definitivamente fechada, sobre o possível substrato genético dos comportamentos homossexuais, conhecida como a busca do "gene gay" (Bullough, 1994, pp. 213-232).

Lancemos um olhar retrospetivo não só sobre a letra dos exames in vivo e post-mortem, como os signos fotográficos que suportavam visualmente a interpretação no século XIX e primeira metade do século XX:

os médicos mantinham-se por isso prudentes: não sustentavam o seu juízo apenas na precisão da descrição oral ou escrita, antes se serviam igualmente das imagens que podiam retirar dos casos estudados. Faziam apelo a desenhadores, gravadores ou fotógrafos, para tentar estabelecer o seu saber sobre uma base visual que desejariam equivalente à visão direta que tinham dos seus pacientes. Procuravam assim obter a imagem mais precisa e o mais exata possível, quer fosse um desenho, moldagem ou fotografia. (Le Mens, 2009, pp. 18-19) 
Daí a relevância absoluta das imagens de Nadar e dos autores portugueses. Tenhamos uma vez mais em atenção a sempre citada tese de Michel Foucault sobre o olhar médico que persegue a transparência absoluta e sem resto do corpo:

um olhar que escuta e um olhar que fala: a experiência clínica representa um momento de equilíbrio entre a palavra e o espectáculo. Equilíbrio precário, pois repousa sobre um formidável postulado: que todo o visível é enunciável e que é inteiramente visível, porque é integralmente enunciável. Mas a reversibilidade sem resíduo do visível no enunciável ficou na clínica mais como exigência e limite do que como princípio originário. A descritibilidade total é um horizonte presente e recuado; sonho de um pensamento, muito mais do que estrutura conceitual de base. (Foucault, 1980, p. 131)

Aplicada ao olhar que a medicina volve sobre o hermafroditismo e a intersexualidade, aquela verdadeira pulsão escópica guia, no entanto, a descrição num sentido muito claro, o de precisar o grau de anomalia dos órgãos (e, decerto, com as respetivas disfunções) relativamente à estrita normalidade binária polarizada pela oposição macho / fêmea, em função de uma possível intervenção corretora que reconduza (se possível, cirurgicamente) o vício de conformação orgânica ao sexo que se afigura à partida mais viável e que será o sexo a (re)atribuir ao indivíduo que assim ficará definitivamente com um "verdadeiro sexo" de "homem" ou de "mulher". Subjacente a isto há uma proibição informulada, que obriga a que, em caso algum, a descrição possa ser de molde a legitimar uma situação ou uma identidade terceira, hermafrodita, intersexual ou outra, suscetível de pôr em causa o dimorfismo sexual:

A ideia de que possa existir uma "verdade" do sexo, na formulação irónica de Foucault, nasce precisamente por meio de práticas reguladoras que geram identidades coerentes numa matriz de normas coerentes de género. A heterossexualização do desejo exige e institui a produção de oposições discretas e assimétricas entre "feminino" e "masculino", entendidas como atributos expressivos de "macho" e o "fêmea". A matriz cultural por meio da qual a identidade de género se tornou inteligível exige que certos tipos de "identidades" não possam "existir" - isto é, aquelas em que o género não é consequência do sexo e aquelas em que as práticas do desejo não são "consequência" nem do sexo, nem do género. (...) De facto, é justamente porque certos tipos de "identidades de género" não se conformam com essas normas de inteligibilidade cultural que ocorrem apenas como transtornos de desenvolvimento ou impossibilidades lógicas no interior desse domínio. (Butler, 2017, p. 80)

Eis porque terá de ser sempre uma impossibilidade prática a existência de um "verdadeiro hermafroditismo" paralelo e em pé de igualdade com o verdadeiro sexo integral e inequivocamente masculino ou feminino. O que os médicos hão-de encontrar sempre será um pseudo-hermafroditismo e nunca o autêntico Santo Graal de um verdadeiro 
hermafroditismo que desminta a categórica invariabilidade do binarismo. A patologização destes indivíduos incoerentes, sempre imperfeitamente homens e imperfeitamente mulheres, porque nunca perfeitamente hermafroditas, constitui-se como apaziguamento formal. Necessário é que o hermafroditismo se confine sistematicamente a um desvio, quer da normalidade masculina, quer da normalidade feminina, que sempre se detenha reconfortantemente pseudo, ainda que, para tanto, tenha de ser suplementado com recurso à cirurgia corretiva. Nesta medida, a utilidade do signo interpretativo que é a fotografia dos hermafroditas manifesta-se sobremaneira, não no mostrar como o indivíduo é, para o deixar ficar como tal, mas quanto ao que se lhe deve poder fazer para o normalizar.

Michel Foucault (1994b, 1999) e Thomas Laqueur (1992) avisaram-nos atempadamente que a preocupação com a definição do verdadeiro sexo dos hermafroditas é tipicamente moderna. Antes da Modernidade, o sexo da criança era determinado formalmente pelo padrinho ou o pai que a batizavam, e, nos casos de posterior discrepância, o indivíduo era autorizado a alterar o seu sexo de pertença, nomeadamente para efeitos de contração de matrimónio, mas optando uma única vez. Nova tentativa de o fazer, isso sim, era sancionada como fraude deliberada do indivíduo que, a pretexto de acidentes da natureza - as conformações sexuais ambíguas - que enganam o observador, dissimula a consciência profunda da sua identidade no intuito de se servir do seu corpo com propósitos criminais ou libertinos, designadamente abatíveis à prática da sodomia (Foucault, 1999, p.62). A tradição médica, da Antiguidade ao Renascimento, tem uma conceção monossexual do dimorfismo sexual: sexo biológico há só um, o masculino, de que o feminino é uma cópia imperfeita, e as mudanças ou as ambiguidades na estrutura corpórea, admitidas sem demasiado sobressalto, como mostra um excerto do padre António Vieira citado por Joaquim Alberto Pires de Lima (1939, p. 7), apenas adquiriam relevância acrescida na medida em que se repercutiam de forma determinante na atribuição social do género. A contrapartida disto, no plano da jurisprudência em que efetivamente existem dois géneros sociais com estatutos inconfundíveis, é que os órgãos não constituem o signo de algo solidamente corpóreo, mas essencialmente os certificados contingentes do estatuto de género cuja precariedade ou ambiguidade, sobretudo no caso dos hermafroditas, não pode ser determinante para a atribuição social daquele: "assim, para os hermafroditas, a questão não era a de saber 'de que sexo são verdadeiramente', mas para que género mais facilmente os inclinava a arquitetura do seu corpo" (Laqueur, 1992, p. 153). Ao invés do que hoje nos é familiar, "a biologia encontra-se submetida a normas culturais, tal como a cultura repousa sobre a biologia" (Laqueur, 1992, p. 161), pelo que, antes da modernidade, "ser homem ou mulher era deter uma posição social, assumir um papel cultural, e não ser organicamente de um ou do outro sexo. O sexo era ainda uma categoria sociológica, que não ontológica" (Laqueur, 1992, p. 161). Só a partir do século XVIII, com as teorias biológicas da sexualidade, as condições jurídicas do indivíduo e as formas de controle administrativo nos Estados modernos, é que a coexistência de dois sexos num só corpo passou a ser problemática, pelo que, do ponto de vista daquilo que Arnold Davidson denominou o "estilo anatómico de raciocínio" 
(Davidson, 2001, p. 32) da medicina moderna, a questão que se põe em presença de um hermafrodita deixa de ser o reconhecimento daquela coexistência para passar a ser decifrar qual é o verdadeiro sexo dissimulado sob os órgãos que possam ter revestido as aparências enganosas do outro sexo, o que faz com que os hermafroditas só possam ser sempre pseudo-hermafroditas. A modernidade acreditou

que é do lado do sexo que há que procurar as verdades mais secretas e mais profundas do indivíduo; que é lá que melhor se pode descobrir o que ele é e o que o determina; e se durante séculos se acreditou que era preciso esconder as coisas do sexo porque eram vergonhosas, sabe-se agora que é o próprio sexo que esconde e as partes mais secretas do indivíduo: a estrutura dos seus fantasmas, as raízes do seu eu, as formas da sua relação com o real. No fundo do sexo, a verdade. (Foucault, 1994b, p. 118)

A partir de Foucault, podemos então perceber como a abordagem médica moderna daquilo que ela percebia como pseudo-hermafroditismo se repercute ainda nos tempos que correm no entendimento, quer da transsexualidade e da transgeneridade, quer da homossexualidade, todas basicamente referidas a alguma forma de inversão das caraterísticas de género, como sublinham Arnold Davidson (2001, pp. 34-35), Edward Stein (1999, pp. 202-205), Alice Domurat Dreger (1998, p. 135), e de equivalente "hermafroditismo psíquico", como aventa Pierre-Henri Castel (2003, pp. 23-31), de tal maneira que uma história do hermafroditismo deveria elucidar a razão pela qual se chegou a condenar por igual esses dois fenómenos perfeitamente distintos que são o hermafroditismo e a homossexualidade (Foucault, 1994a, p. 625). Embora muito mais se pudesse dizer para o demonstrar, esta matriz epistémica da scientia sexualis é aquilo que, em última análise, explica a contaminação recíproca entre hermafroditismo e intersexualidade, por um lado, e, por outro, travestismo, homossexualidade(s), transgeneridade(s) e transsexualidade(s), etc. que se faz notar desde os primórdios do estudo do hermafroditismo (Dreger, 1998, pp. 126-138), o que só contribui para a incomodidade dos clínicos, e que orienta os excursos históricos com que alguns médicos portugueses parecem acreditar contribuir para esclarecer estas questões, inadvertidos do confusionismo metodológico com que as formulam, a partir dos parâmetros culturais que enformam a sua "vontade de saber". Joaquim Alberto Pires de Lima é quem melhor o ilustra, embora não seja exemplo isolado (Aguiar, 1928) nos seus estudos "Hermafroditismo e inter-sexualidades" (Lima, 1939) e Vícios de conformação do sistema uro-genital (Lima, 1930), este último profusamente ilustrado com desenhos e fotografia, ao longo dos quais o autor passa sumariamente em revista a mitologia greco-latina, a tematização literária no romance popular da "Donzela que vai à guerra", além da tradição literária nacional, desde as lésbicas do Cancioneiro Geral de Garcia de Resende e de Fialho de Almeida e do Conde de Vila-Moura, ao hermafrodita de Eugénio de Castro, e ao travesti de Vagos que está na origem do filme mudo Rito ou Rita (1927), de Reinaldo Ferreira, os casos históricos de Antónia/António Rodrigues e de Maria Pacheco, este referido por Amato Lusitano, no Renascimento, e de Henriqueta Emília da Conceição, Bernardina de Sena 
e a Maria-Homem observadas respetivamente por May Figueira e por Vicente José de Carvalho, no século XIX, além dos seus próprios casos, no início do século XX (Lima, 1930, pp. 1-33; Lima, 1939, pp. 3-14). A preocupação insistente que percorre as suas páginas é a negação da própria possibilidade de um qualquer hermafroditismo de perto ou de longe suscetível de ser estabelecido como verdadeiro: "não me ocupo neste livro do hermafroditismo verdadeiro, por não haver caso nenhum registado em Portugal" (Lima, 1930, p. 113, nota 2). Num gesto que naturaliza o interdito bíblico de violação do dimorfismo sexual binário, Pires de Lima (1939, p. 3), invoca os "livros sagrados que solenemente condenam qualquer tentativa de confusão dos sexos" (Lima, 1930, p. 1), o que mostra que, ao contrário do que acontecia nas sociedades pré-modernas, o hermafrodita é comparado com uma espécie de falsificador que ludibria por intermédio do seu corpo, não imediatamente a boa ordem social, mas a própria ordem natural das coisas, sobre a qual velam os saberes médicos, e social, e dela cuidam os saberes jurídicos (Le Mens, 2009, p. 12). Explica Dreger que:

para um médico, admitir o verdadeiro hermafroditismo de um duvidoso indivíduo vivo, teria equivalido a contribuir potencialmente para a ameaça de confusão social dos sexos fomentada por gente como as feministas e os homossexuais (...) Temos de recordar que a tarefa de distinguir e manter separados os "verdadeiros" homens, as "verdadeiras" mulheres e os "verdadeiros" hermafroditas nunca foi encarada como meramente académica ou como um exercício isolado. As definições de "verdadeiro" e "espúrio" hermafroditismo e de "sexo verdadeiro" sempre acarretaram implicações políticas. (Dreger, 1998, p. 153)

Se o hermafroditismo verdadeiro equivale a uma impossibilidade que tanto é moral como ontológica, o sexo verdadeiro, em contrapartida, passa por um imperativo que orienta o olhar médico, desde o diagnóstico até à intervenção corretora que, no século que medeia sensivelmente entre 1850 e 1950 (mas com ramificações que se estendem até aos nossos dias), se afigurava porventura mais mandatória e reconfortante para os clínicos do que para os seus pacientes, persistente e espantosamente mudos, ou emudecidos, durante todo esse tempo. O modo como Pires de Lima trata o caso de Inês dos Anjos é esclarecedor:

caso deveras curioso de pseudo-hermafroditismo masculino, que observei a 6-III-923. (...) Segundo afirma, tem frigidez sexual completa. A sua voz é masculina, bem como a conformação do seu corpo. Afirmou que era menstruada desde os 16 anos e indignou-se quando the disse que era um rapaz. - "Eu sou Inês, trago saias e mijo por baixo como as mulheres; como quer que o senhor que eu seja homem?" (...) Inês dos Anjos é um pseudo-hermafrodito masculino (...) A inteligência de Inês é rudimentar. Foi presa no Porto por causar suspeitas à polícia e foi por essa ocasião que pude observá-la. (...) A imprensa portuense referiu-se largamente a esta 
mulher-homem. Quatro anos mais tarde, passou-se idêntica scena em Lisboa. Inês dos Anjos foi ali presa, mas desta vez levaram-na ao Hospital da Estefânia, onde foi operada, a 7 de Abril de 1927 (...) Só então se convenceu que era realmente macho e passou a denominar-se Inácio. (Lima, 1930, pp. 110-113)

O que teríamos ficado a saber se se ressubjetivassem como interlocutores capacitados para falar em nome próprio - o que só logrou impor-se em tempos de pós-modernidade (Dreger, 1998, pp. 167-168) - as pessoas produzidas, quer como objetos, quer como sujeitos, isto é, objetificadas como espécimes patológicos (pseudo)hermafroditas e subjetivadas como pacientes matéria-prima da intervenção médica, em que a fotografia desempenha um indispensável papel amordaçante? O caso único de Herculine Barbin / Alexina B. é particularmente revelador, a despeito da sua desautorização por Tardieu que lhe publica o diário tão-só para o expurgar, num esforço de o re-capturar para a scientia sexualis que lhe desqualifica a palavra própria. No estudo sobre esse relato em primeira pessoa - de resto muito manipulado criticamente por Judith Butler com os seus próprios intuitos, atinentes sobretudo às condições da identidade lésbica de Alexina e sem repercussão direta para a presente análise (Butler, 2017, pp. 200-221) - Foucault ajuda a perceber como o suicídio de Herculine / Alexina se pode explicar pela sua total inadaptação à nova identidade estritamente masculina que lhe foi imposta preciamente quando el@ não via necessidade de deixar o seu anterior limbo de não-identidade perfeitamente consonante com a sua anatomia, pela qual não se sentia traída (Foucault, 1994a, p. 624), como pode ocorrer com alguns transsexuais atuais (Santos, 2012, p. 63), sobretudo quando o quadro de referência do seu intenso desejo de mudar para o "seu" verdadeiro sexo é o de uma forte polaridade bissexual/binária:

o conceito de pertença de todo o indivíduo a um sexo determinado foi formulado pelos médicos e os juristas somente à volta do século XVIII. Mas na realidade, será que se pode sustentar que cada um dispõe de um sexo verdadeiro e que o problema do prazer se põe em função desse pretenso sexo verdadeiro, quer dizer, do sexo que cada um devia assumir, ou descobrir, se for ocultado por uma anomalia anatómica? (Foucault, 1994a, p.624)

É inegável a responsabilidade que tem por este estado de coisas o modelo biomédico de correção cirúrgica que entende o (pseudo) hermafroditismo como falha, disfunção ou deficiência essencial que compromete a ortogénese do indivíduo desejavelmente portador de, e reconhecível por, uma canónica coerência entre sexo biológico, desempenho social de género e subjetividade sexual. $\mathrm{Na}$ verdade, a retificação cirúrgica que tendem a propor os clínicos portugueses e internacionais como panaceira sistemática para os tão obscuros como expeditivos "vícios de conformação anatómica" pode e deve ser entendida como instrumento atuante no interior da ordem compulsória entre sexo, género e desejo e à luz crítica que sobre ela lançou a crip theory de Robert McRuer, mostrando como o capacitismo compulsório [compulsory able-bodiedness] se 
cruza intimamente com a heterossexualidade compulsória: "o sistema do capacitismo compulsório, que em certo sentido produz a deficiência, encontra-se meticulosamente entretecido com o sistema da heterossexualidade compulsória que produz a divergência sexual [queerness] (...) a heterossexualidade compulsória é dependente do capacitismo compulsório, e reciprocamente" (McRuer, 2006, p. 2).

Casos exemplificativos disto mesmo são os que passaram pelas mãos do médico José Bacalhau descritos num artigo cujo significativo título "Duas palavras de advertência sobre erros de diagnóstico do sexo" verifica tudo o que atrás adiantámos. No primeiro, ocorrido em 1944 nos Hospitais da Universidade de Coimbra, a transformação, por vontade expressa pela própria, de Rosa das Neves, criança impúbere que aos 9 anos de idade apresenta um pequeno pénis que simula um clítoris hipertrofiado e dois bordeletes longitudinais que simulam os lábios vulvares, em António Rosa das Neves, que vemos fotografado no "antes", como rapariga, e no "depois", como rapaz, parece "radiantíssima por se ver com um fato de rapaz e se encontrar transferida para as fileiras do sexo masculino" (Bacalhau, 1946, p. 62), "que ele ainda julga forte, ignorando quanto o homem se tem desacreditado, nos últimos anos deste hemi-século" (Bacalhau, 1946, p. 63). Menos risonho é o caso da criança de dois anos e meio, batizada como Maria Lúcia P., que apresenta hipospádia perineal com um pénis rudimentar e divisão total do escroto que simula o sulco profundo de uma vulva (Figura 2). Confrontado com a perceção extremamente traumática dos pais, agravada pelo ostracismo social, Bacalhau estima que a intervenção uretroplástica é inviável, e expeditamente decide prevenir as consequências do futuro surgimento de carateres secundários masculinos (barba, voz grave, fácies másculo, etc.):

quanto a nós, sob o ponto de vista social e familiar, só há um caminho a seguir - a castração - para evitarmos maldosas zombarias do povo e afagarmos o desgosto destes infelizes. Deste modo, prevenimos o aparecimento dos carateres somáticos do sexo masculino e a criança continuará a ser considerada mulher, através de toda a sua vida, dedicando-se aos sobrinhos e outros parentes, se os tiver. É mais um eunuco e quem sabe se virá a ser um valor útil à sociedade ou um guarda fiel de haréns ocidentais. Seja como for, torna-se necessário evitar o ridículo e o desgosto, recorrendo à castração. (Bacalhau, 1946, pp. 68-69)

De forma terrivelmente enviesada, Bacalhau dá razão à ideia de "mulher eunuco", deplorada pela feminista Germaine Greer, acabando por atribuir ao papel cuidador das mulheres, sobretudo daquelas que vê como "tias" não "realizadas" pelo casamento, o estatuto de indício da essencial incompletude da feminilidade, em estreita dependência ontológica do princípio masculino. 


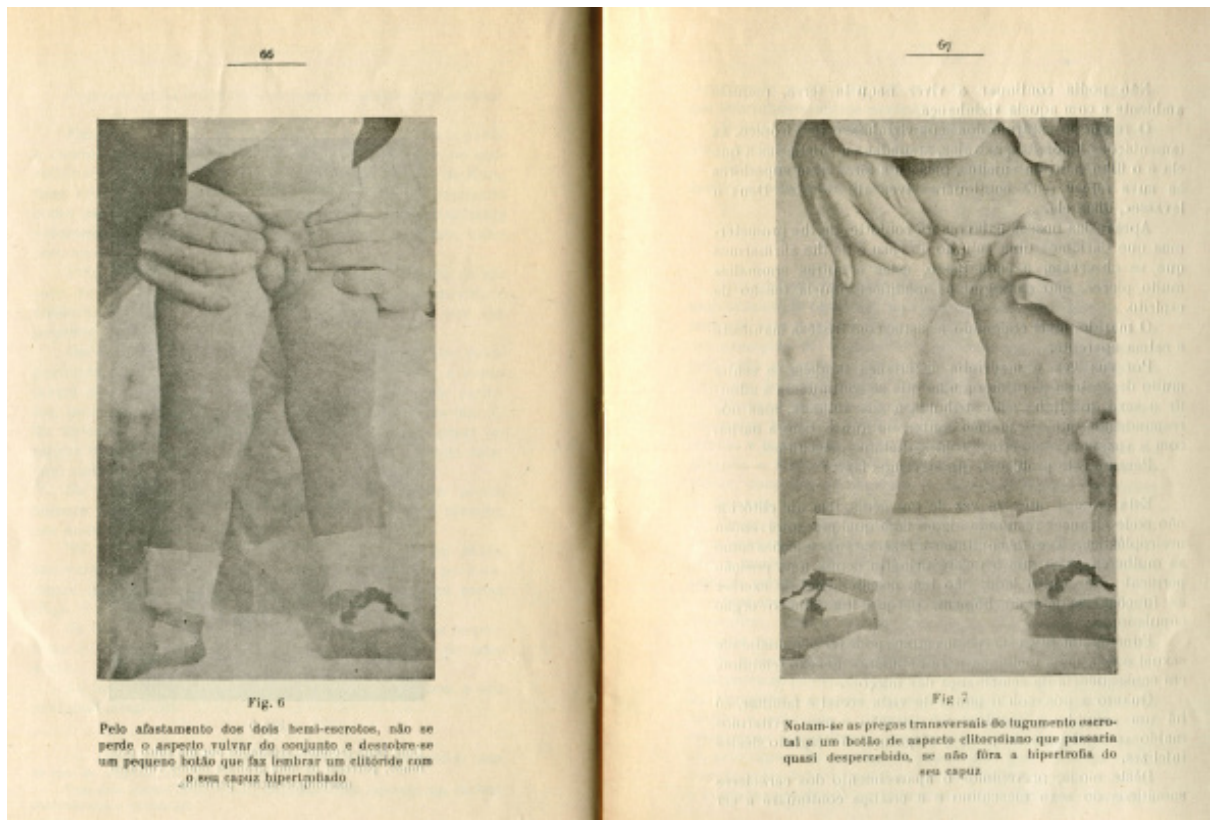

Figura 2: Caso de Maria Lúcia P., observada por José Bacalhau em 1945 Fonte: Bacalhau, 1945, pp. 66-67

Claramente, somos com isto remetidos para o plano do monstruoso, que outro médico, Jorge Alberto Martins D’Alte, explicita de forma eloquente a propósito de um recém-nascido cujo sexo determina ser o masculino, a despeito da ausência de testículos, com hipospádias perineal e criptorquídea, que o clínico acrescenta ser um fenómeno frequente nestes casos:

todos sabem que, na Natureza, ao lado de indivíduos com sexo distinto, há outros que produzem, lado a lado, gâmetas masculinos e femininos. São os hermafroditos. Nos animais superiores, este fenómeno é excepção e apresenta-se sempre num grau rudimentar. Nos Mamíferos, e portanto no Homem, é considerado como um caso teratológico e distingue-se então o hermafroditismo verdadeiro e o pseudo-hermafroditismo. No primeiro pode haver um ou dois ovo-testis, ou ainda a coexistência de um ovário e de um testículo independentes; no segundo, a uma determinada gónada, correspondem órgãos sexuais e carateres sexuais secundários, que parecem caraterizar o sexo oposto. (D'Alte, 1945, p. 5)

Curiosamente, com este caso, a ciência médica parece poder aproximar-se mais facilmente das teratologias pré-modernas do estranho e do distante nos mundos animal e humano, tais como as de um Ambroise Paré (Davidson, 2001, p. 33), de resto citado por Pires de Lima (Lima, 1930, p. 19), entre muitos outros, do que do efetivo estatuto que a pré-modernidade atribuía aos seus semelhantes hermafroditas com quem convivia nas sociedades europeias. Barbara Maria Stafford esclareceu tais analogias entre países e regiões distantes e costumes estranhos e remotos e os recessos obscuros e profundos do corpo: 
estas retorcidas analogias dependem do estabelecimento de um movimento do inferior para o superior, da aparência para a essência, do público para o privado, da superfície para a profundidade, do visual para o verbal, do conhecido para o desconhecido. Tais correspondências hierárquicas entre o exterior e o interior de algo movem-se fundamentalmente em torno do facto de o conteúdo de um dos termos deste par (aquele que está ontologicamente "acima") ser invisível, incerto, ou nuclear relativamente ao outro (aquele que está ontologicamente "abaixo"). (Stafford, 1992, pp. 28-29)

A fotografia médica dos hermafroditas dava um contributo determinante para uma representação científica da fealdade que desmentia a representação artística clássica do hermafrodita como o composto das perfeições estéticas de ambos os sexos (Stafford, 1992, p. 158). A recuperação do tema nas artes modernas começou a levantar objeções que aliavam a repugnância moral ao desprazer estético que, desse modo, principia a deslizar para o terreno do obsceno, o que se agravou com o reconhecimento científico da existência de espécies hermafroditas na natureza e que a ciência pós-Lineu principia a descrever, percebendo-as como fruto de procriações aberrantes de que resultavam monstros e que já nada tinham a ver com a idealização estético-mitológica da unidade perfeita (Stafford, 1992, pp. 265-266), pelo que os hermafroditas animais e humanos passam a engrossar o estendal de deformidade patológica que confina com o monstruoso e o grotesco, um erro de combinatória na gramática natural dos seres vivos, tanto mais disforme quando ocorre nos escalões superiores da suposta hierarquia taxonómica coroada pelo humano (Stafford, 1992, p. 276).

A monstrificação do indivíduo hermafrodita ou intersexual tem por eixo de sentido a sua abordagem como "erro" constitutivo (Mourão \& Guedes, 2006, pp. 192-193) que dissimula sob o jargão médico do erro de diagnóstico o quão errada é a própria existência dessas pessoas enquanto erro da natureza ainda antes de supostamente induzirem em erro o olhar médico. Tanto explica que a fotografia dos hermafroditas não constitua apenas um suporte do saber científico, sendo antes um retrato equivalente ao "do paciente que permite impressionar os sentidos ou o ambiente sensório do espetador" (Le Mens, 2009, p. 31). É através deste filtro que a curiosidade médico-científica para com a malformação e a deformidade apropria nos termos que lhe são próprios as monstruosidades de toda a espécie cujo estatuto quimérico primitivamente avizinhava os hermafroditas humanos de toda a espécie de anatomias fantásticas, tanto humanas como animais. Nem por isso os hermafroditas deixam de permanecer monstros sociais que, ao porem em causa a diferença entre os sexos, veiculam uma forma de perigo social tal como ele é entendido pela sociedade burguesa da época (Le Mens, 2009, p. 10). Recorda Foucault a este propósito que só com o surgimento de uma scientia sexualis, que principia pela organização anatómica da sexualidade, é que se passará a reconhecer a monstruosidade moral lá mesmo onde deixa de se ver a monstruosidade da natureza. Comum à obra do Marquês de Sade, surge assim a figura do monstro moral, do criminoso monstruoso, no qual a infração mais extrema se junta à aberração da natureza, a qual passa a funcionar como origem causa e quadro daquela (Foucault, 1999, pp. 68-70). 
Que a inadmissibilidade da existência de um verdadeiro hermafroditismo persiste intacta mesmo nos casos que alguns médicos nacionais muito relutantemente classificam como verdadeiros, dos muito raros casos congéneres a nível mundial - para logo se apressarem a desmenti-los, na prática, com a sua retificação cirúrgica - confirmam-no António Carneiro de Moura e Ludgero Pinto Basto na pessoa de Joaquim António T., de 19 anos (Figura 3). Referenciado por médicos que detetaram o caso no meio rural alentejano de onde provinha, com queixas de hemorragias uretrais ao longo de quatro anos, os exames radiológicos e endoscópicos estado-da-arte que lhe são feitos no Hospital de Santa Maria revelam a existência de próstata, um testículo esquerdo funcionante com produção de espermatozóides e, em simultâneo, ausência de orifício vaginal e menstruação exteriorizada pela uretra, ginecomastia e presença de útero, ovário e trompa plenamente conformados, mas apenas do lado direito, onde o exame histológico pós-operatório mostra inclusive quistos foliculares e endometriose heterológica exclusivas do aparelho reprodutor feminino. Extirpados os órgãos femininos por laparotomia mediana infra-umbilical, numa verdadeira histerectomia total (Basto \& Moura, 1945, p. 276), mas deixados intocados os volumosos seios que a fotografia faz saltar à vista, o jovem retoma a atividade heterossexual, "tendo praticado o coito com sucesso" (Basto \& Moura, 1945, p. 278).

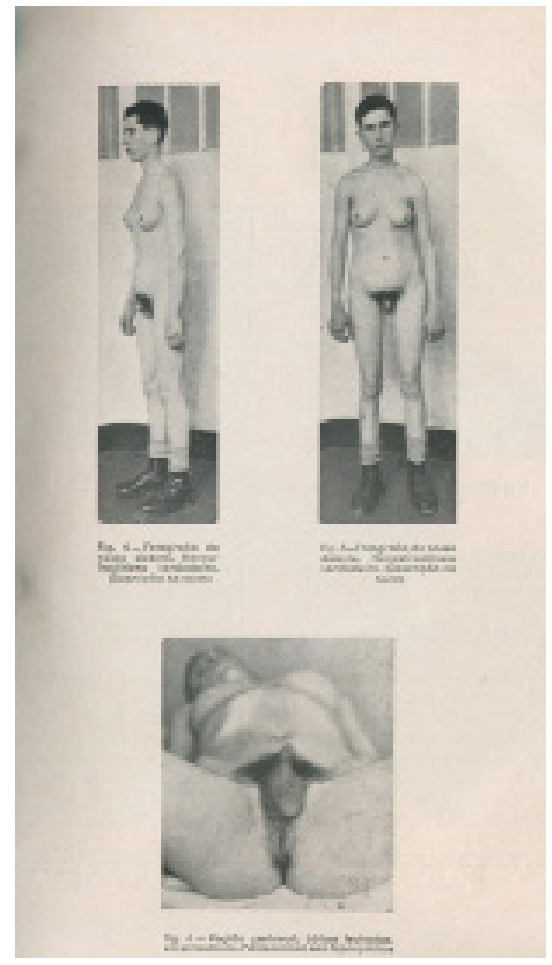

Figura 3: Caso de Joaquim António T., estudado por António Carneiro de Moura e Ludgero Pinto Basto em 1944 Fonte: Moura \& Basto, 1944

Se nada ficamos a saber das razões desta opção, nem a quem assacar a responsabilidade por este rumo dos acontecimentos, o certo é que a atitude médica sugere nenhuma complacência para com o sexo que tanto lhes parece ser o mais fraco que a sua normalização cirúrgica, por assim dizer tecnogenérica, é tudo menos dramática: 
género é uma noção necessária para o aparecimento e o desenvolvimento de uma série de técnicas farmacopornográficas de normalização e transformação do ser vivo - como a fotografia dos 'desviantes', a identificação celular, a análise e a terapia hormonais, a leitura cromossómica ou a cirurgia transsexual e intersexual. Será por isso mais correto, em termos ontopolíticos, falar de 'tecnogénero' se queremos dar conta do conjunto de técnicas fotográficas, biotecnológicas, cirúrgicas, farmacológicas, cinematográficas ou cibernéticas que constituem performativamente a materialidade dos sexos. (Preciado, 2008, p.86)

A conclusão a que chega Anne Fausto-Sterling, que chegou a propor a existência de cinco géneros distintos (Fausto-Sterling, 2012, p. 103), só pode pois ser considerada definitiva a este respeito: "traçar a história das abordagens médicas da intersexualidade ensina-nos de modo mais geral como variou a própria história social do género. De caminho, ficamos a saber que nada há de natural ou de inevitável no tratamento médico atual dos intersexos" (Fausto-Sterling, 2012, p. 54). Mesmo assim, et pour cause, perante a transferência da correção cirúrgica do hermafroditismo e da intersexualidade, vistos como disfuncionais, do domínio do puro paternalismo médico autoritário para a satisfação das solicitações terapêuticas de uma clientela cidadã inquestionavelmente detentora de direitos (Santos, 2013, p.4), não deixa de ser legítimo interrogarmo-nos acerca do otimismo tecnológico que parece transferir-se por igual:

é notável que a abordagem médico-tecnológica reine na medicina do intersexo, a despeito do facto de os especialistas em intersexo depressa confessarem que a intersexualidade não consiste primariamente num problema médico, mas antes um problema social. Os peritos em intersexualidade presumem que, ao restituírem tecnologicamente os intersexuais às categorias anatómicas de "macho" e "fêmea", esses indivíduos deixarão de ser intersexuados - e que o problema social será evitado ou eliminado. (Dreger, 1998, p. 186)

Inspirando-se nas fotografias de Nadar, Beatriz/Paul Preciado tem toda a razão ao dizer que a invenção da fotografia no século XIX seria crucial para a produção do novo sujeito sexual e da sua verdade visual na medida em que confere pela primeira vez um valor de realismo visual à produção técnica do corpo, outrora entrega ao desenho anatómico e à ilustração pornográfica (Preciado, 2008, p. 87):

os órgãos sexuais são expostos ao olhar fotográfico por uma mão externa. A imagem dá conta do seu próprio processo de produção discursiva. Compartilha os códigos da representação pornográfica que surgem nesta mesma época: a mão do médico oculta e mostra ao mesmo tempo os órgãos sexuais, estabelecendo assim uma relação de poder entre o sujeito e o objeto da representação. (...) A verdade do sexo adquire aqui o caráter de uma revelação visual, processo no qual a fotografia participa como um 
catalisador ontológico que explicita uma realidade que não poderia mani-

festar-se de outro modo. (Preciado, 2008, p. 87)

A agressividade das mãos invasivas e impúdicas do clínico que assiste à sessão fotográfica de Nadar, não só explica a sua organização numa ordem progressiva que segue a do exame médico (Le Mens, 2009, p. 19), como atesta a autoridade médica, porquanto as mãos aparecem também em desenhos, não constituindo um mero artefacto fotográfico (Dreger, 1998, p. 48). Ela repete-se nas mãos dos médicos portugueses José Bacalhau (1946, pp. 61-62, 65-67), Pires de Lima (1930, pp. 102-134) e Amândio Tavares (1930, Estampa II, extratexto), Martins D’Alte (1945, pp. 3-4), Carneiro de Moura e Pinto Basto (1945, p. 271) que agarram, seguram, erguem e repuxam os órgãos dos hermafroditas que pretendem evidenciar, e chegam inclusive a escancarar-lhe os orifícios, como descrevera Herculine Barbin (Le Mens, 2009, p. 23), oferecendo-os à lente obscena da câmara que os devassa sem pejo, com um voyeurismo que, temos de admitir, é comum tanto ao olhar médico, como à cultura popular e às artes visuais e que a fotografia convoca por igual. Não é pois possível dissociar o registo fotográfico dos hermafroditas, que produzia imagens detalhadas dos órgãos genitais e dos carateres sexuais secundários, supostos reveladores da morfologia geral do homem e da mulher, da convicção que os saberes médicos mantêm até à década de 1930 - a julgar pelo presente estudo, diríamos que o panorama se mantém entre nós sensivelmente até meados da década de $1940-$ quanto à sua capacidade de determinar aquilo que acreditam ser o verdadeiro sexo de uma pessoa hermafrodita sob aquilo que se entendia como anomalia(s) ou vício(s) de conformação urogenital. Diz-nos Le Mens que, na prática, essa determinação era difícil e mesmo impossível em numerosos casos, até ao advento da cirurgia assética atual, que permitia revelar o interior do corpo humano vivo e ao recurso ao exame histológico microscópico das gónadas (Le Mens, 2009, pp. 12-13).

Podemos interrogar-nos se esse olhar que, na demanda da identidade do sujeito, desce do rosto até à genitália, não se terá ainda de algum modo transmitido a uma exploração que, hoje, desce a maiores profundidades ainda, genéticas, neuronais, as que trespassam a pele e as mucosas. O espólio que nos resta daquela antiga obstinação médica, além do seu inegável valor documental e museológico, deve ser-nos útil para discernirmos o quanto desse passado foi realmente superado pela atualidade que doravante nos interpela.

\section{REFERÊNCIAS BIBLIOGRÁFICAS}

Aguiar, A. A. de (1928). Pseudo-hermafroditismo feminino: caso português do século XVII. Archivo de Medicina Legal, Vol. II, 4, 432-436.

Athias, M. (1937). Problemas actuais de endocrinologia sexual. Actualidades Biológicas, X, 99-159.

Bacalhau, J. (1946). Duas palavras de advertência sobre erros de diagnóstico do sexo. Arquivo de Propedêutica Cirúrgica, IV, 47-70.

Barbin, A. H. (1978). Herculine Barbin dite Alexina B. Présenté par Michel Foucault. Paris: Gallimard. 
Basto, L. P. (1949). Uma prova para o diagnóstico do sexo no Pseudo-hermafroditismo em idade pré-puberal. Boletim de Endocrinologia e Clínica, II, 4.

Basto, L. P. \& Moura, A. C. (1945). Hermafroditismo verdadeiro. Amatus Lusitanus, IV, 4, 263-281.

Borges, R.; Versos, R.; Louro, N.; Massó, P.; Vila, F.; Osório, L.; Cavadas, V.; Carvalho, A.; Gandra, H.; Monteiro, M.; Fuente, J. La \& Marcelo, F. (2006). Pseudohermafroditismo masculino. Reatribuição de género por deficiência de 17-hidroxiesteroide deshidrogenase. Revista Internacional de Andrología, 4, 39-41.

Bullough, Vern L. (1994). Science in the Bedroom. Nova lorque: Basic Nooks.

Butler, J. (2017). Problemas de género. Lisboa: Orfeu Negro.

Castel, P.-H. (2003). La métamorphose impensable. Essai sur le transsexualisme et l'identité personelle. Paris: Gallimard.

Chaves, P. (1925). Hermafroditismo. Gazeta da Relação de Lisboa - Revista Crítica dos Tribunais, 18, $273-274$.

Crary, J. (2001). Suspensions of Perception. Attention, Spectacle, and Modern Culture. Cambridge: The MIT Press.

D’Alte, J. A. M. (1945). Diagnóstico de um pseudo-hermafrodito masculino humano antes do baptismo. Folia Anatomica Vniversitatis Conimbrigensis, $X X(\mathrm{I})$, 1-7.

Davidson, A. L. (2001). The Emergence of Sexuality. Cambridge: Harvard University Press.

Dreger, A. D. (1998). Hermaphrodites and the Medical Invention of Sex. Cambridge e Londres: Harvard University Press.

Fausto-Sterling, A. (2012). Corps en tous genres. La dualité des sexes à l'épreuve de la science. Paris: Éditions La Découverte.

Figueira, C. M. (1864). Observação de um caso de hermafroditismo masculino colhida no Hospital de S. José. Gazeta Médica de Lisboa, 200-211, 235-242.

Fonseca, A. (1970-1971). Determinação psicológica do sexo e seus desvios. Aspectos psiquiátricos do intersexo. Trabalhos do Laboratório de Anatomia e Patologia Geral do Porto, XXVIII, 65-75.

Fontes, V. (1937). Contribuição para o estudo da precocidade sexual. Arquivo de Anatomia e Antropologia, 18, 113-174.

Fontes, V. (1926). Notas sobre um caso de anomalia dos órgãos sexuais externos. Arquivo de Anatomia e Antropologia, X, 303-314.

Foucault, M. (1999). Les anormaux. Paris: Gallimard / Le Seuil.

Foucault, M. (1994a). Le mystérieux hermaphrodite. In Dits et Écrits 1954-1988. III - 1976-1979 (pp. 624-625). Paris: Éditions Gallimard.

Foucault, M. (1994b). Le vrai sexe. In Dits et Écrits 1954-1988. IV - 1980-1988 (pp. 115-12). Paris: Éditions Gallimard.

García, F. V. \& Cleminson, R. (2012). Los hermafroditas. Medicina e identidade sexual en España (1850-1950). Granada: Editorial Comares. 
Guinzburg, C. (1979). Spie. Radici di un paradigma indiziario. In A. Gargani (Ed.), Crisi della ragione (pp. 57106). Torino: Einaudi.

Laqueur, T. (1992). La fabrique du sexe. Paris: Gallimard.

Le Mens, M. \& Nancy, J.-L. (2009). L’hermaphrodite de Nadar. Nantes: Éditions Créaphis.

Lima, J. A. P. (1930). Vícios de conformação do sistema uro-genital. Porto: Araújo \& Sobrinho, Suc. ${ }^{\text {res }}$.

Lima, J. A. P. (1937a). Hipospadias e erros de sexo (Comunicação à II Reunião da Sociedade Anatómica Portuguesa, Porto, Setembro de 1934). Arquivo de Anatomia e Antropologia, 18, 43-48.

Lima, J. A. P. (1937b). Hipospadias e erros de sexo (Comunicação à II Reunião da Sociedade Anatómica Portuguesa, Porto, Setembro de 1934). Arquivo da Repartição de Antropologia Criminal, Psicologia Experimental e Identificação Civil do Pôrto, f. 2, III

Lima, J. A. P. (1939). Hermafroditismo e inter-sexualidade. Separata de A Medicina Contemporânea, 44, 3-19.

Lima, J. A. P. \& Tavares, A. (1930). Deux cas de pseudo-hermaphroditisme masculin. Folia Anatomica Conimbrigensis, V(9), 1-17.

McRuer, Robert (2006). Crip Theory. Cultural Signs of Queerness and Disability. Nova lorque \& Londres: New York University Press.

Mira, M. F. de (1933). Porque nascemos homem ou mulher? Actualidades Biológicas, V, 208-239.

Moura, A. C. \& Basto, L. P. (1945). Hermafroditismo verdadeiro. Amatus Lusitanus - Revista de Medicina e Cirurgia, IV, 263-284.

Mourão, J. A. \& Guedes, M. E. (2006), Os monstros no naturalismo. In A. L. Pereira e J. R. Pita (Eds.), Miguel Bombarda (1851-1910) e as singularidades de uma época (pp. 189-196). Coimbra: Imprensa da Universidade de Coimbra.

Pimentel, J. C. (1996). A documentação pela imagem em medicina. História da sua utilização em Lisboa. Lisboa: Universitária Editora.

Pinto, M. E. S. (1915). Alguns Casos de Pseudo-Hermafrodismo. Lisboa: Instituto de Medicina Legal.

Preciado, B. (2008). Testo yonqui. Madrid: Espasa Calpe.

Santos, A. L. F. (2012). Um sexo que são vários. A (im)possibilidade do intersexo como categoria humana. Dissertação de Mestrado. Universidade de Coimbra, Coimbra, Portugal. Retirado de https:// estudogeral.sib.uc.pt/handle/10316/20210

Santos, A. L. F. (2013). Para lá do binarismo? O intersexo como desafio epistemológico e político. Revista Crítica de Ciências Sociais, 102, 3-20.

Stafford, B. M. (1992). Body Criticism. Imaging the Unseen in Enlightenment Art and Medicine. Cambridge \& Londres: The MIT Press.

Stein, E. (1999). The Mismeasure of Desire. Oxford: Oxford University Press.

Vieira, L. (1906). O hermaphroditismo. Movimento Médico - Revista Quinzenal de Medicina e Cirurgia, 20, 321-323. 


\section{Nota BiográficA}

António Fernando Cascais é Professor Auxiliar da Universidade Nova de Lisboa. Foi investigador responsável dos Projetos FCT de I\&D: "História da Cultura Visual da Medicina em Portugal" e "Modelos e Práticas de Comunicação da Ciência em Portugal". Organizou os livros: Hospital Miguel Bombarda 1968 - Fotografias de José Fontes (Documenta, 2016), Cinema e Cultura Queer / Queer Film and Culture (Lisboa, 2014), Olhares sobre a Cultura Visual da Medicina em Portugal (Unyleya, 2014), Indisciplinar a teoria (Fenda, 2004), A sida por um fio (Vega, 1997).

E-mail: afcascaisı@gmail.com

António Fernando Cascais. Rua das Praças, 13B, cave 1200-765 Lisboa, Portugal

* Submetido: 15-08-2017

* Aceite: 30-09-2017 